\title{
NOTAS INTRODUTÓRIAS PARA O ESTUDO DA TEORIA DA HISTÓRIA
}

\author{
INTRODUCTORY NOTES TO STUDY \\ THEORY OF HISTORY
}

DOI: http://dx.doi.org/10.15448/2178-3748.2018.1.24648

\author{
Augusto da Silva \\ Doutor em História (USP) - Professor da UFS \\ augustodasillva@gmail.com
}

\begin{abstract}
RESUMO: O artigo busca oferecer considerações introdutórias para o estudo da teoria da história. O objetivo é apresentar alguns traços do longo e dificultoso processo de construção do discurso historiográfico em suas conexões com a teoria e as reflexões filosóficas sobre a história. Inicialmente, aborda a questão da importância de uma teoria da história para a atividade historiográfica. Toda narrativa histórica se apoia, de maneira refletida ou não, em alguma visão de mundo, numa teoria, e, portanto, é fundamental ao historiador que ele tenha domínio sobre ela. Na sequência, propõe-se uma breve reflexão da complexa interlocução entre historiadores e filósofos acerca de um conhecimento histórico racional. A emergência de um discurso historiográfico científico, no século XIX, se constituiu em contraposição às Filosofias da História iluministas. Os princípios dessa "ciência histórica" amparavam-se muito mais nas técnicas de eruditos especialistas da análise de manuscritos antigos (hermenêutica, filologia, paleografia, diplomática, dentre outras) e na tradição narrativa de eventos particulares do que nas discussões teóricas elaboradas sobre a história.
\end{abstract}

PALAVRAS-CHAVE: História, Teoria da História, Filosofia da História.

ABSTRACT: The present article searches for providing remarkable considerations for the theory of history studies. The aim is to present some features of long and difficult construction process of historiographical discourse in its connections with theory and philosophical reflections on the history. Firstly, addresses the issue of the importance of a theory of history to the historiographical activity. All historical narrative advocates on a reflected manner or not, on some worldview, on a theory, and therefore it is crucial to the historian that he has dominion over it. Following, a brief reflection on the complex dialogue between historians and philosophers about a rational historical knowledge is proposed. The emergence of a scientific historiographical discourse in the nineteenth century, was formed in opposition to the Enlightenment Philosophies of History. The principles of this "historical science" sheltered him a lot more in the technical expert scholars analysis of ancient manuscripts (hermeneutics, philology, paleography, diplomatic, among others) and in the narrative tradition of particular events than in the elaborate theoretical discussions about the history.

KEYWORDS: History, Theory of History, Philosophy of History.

\section{INTRODUÇÃOO}

Este texto nasceu da necessidade de oferecer aos graduandos do curso de História uma introdução à disciplina de Teorias da História. De maneira mais específica, ele 
busca apresentar reflexões em torno do longo embate entre historiadores e filósofos na construção de um discurso histórico racional.

Um elemento central nesse processo é que a possibilidade de uma narrativa histórica científica foi objeto tanto por parte de filósofos quanto de historiadores, a despeito do difícil, tortuoso - quando não inexistente -, diálogo entre eles. De raiz histórica comum, a Grécia Antiga, esses dois campos de saber percorreram um longo percurso até que fosse possível uma reflexão compartilhada sobre a teoria da história, o que de fato só se consolidaria no século XX. Na fundamentação de uma ciência da História por parte de muitos historiadores, no século XIX, a identidade da História se firmava em contraposição - ou, pelo menos, com restrição - às teorias e às filosofias da história de então. Para Leopold von Ranke, a história, ciência do único, do particular, colocava-se em "inabalável oposição" à ideia suprema e o interesse universal da filosofia (2010, p. 145). No manifesto de abertura da Revue Historique, em 1876, Gabriel Monod dizia que a revista seria "um repertório de ciência positiva e de livre discussão, mas ela se limitará ao domínio dos fatos e permanecerá fechada às teorias políticas ou filosóficas" (2010, p. 350). C. Langlois e C. Seignobos, ainda que não assumindo uma postura de aversão à Filosofia da História que, segundo eles, nutria Fustel de Coulanges, advertiam no seu manual de 1898: "dela não cuidaremos aqui”" (1946, p. 5).

Os filósofos, por sua vez, demarcavam seu distanciamento diante da historiografia. Voltaire, o inventor do neologismo "filosofia da história", dizia não estar preocupado com as histórias particulares dos homens, presas num tempo e espaço específicos; buscava a história do homem como ser universal. "Só os filósofos deveriam escrever História" teria dito ele (Apud DURANT, 1996, p. 217).

Karl Marx demostrava certo menosprezo até pelos mais eminentes historiadores alemães, como Leopold von Ranke, “'o mentiroso catador de detalhes’, que reduziu a história a um 'anedotário fácil e atribuiu todos os grandes acontecimentos a causas insignificantes e mesquinhas"” (Carta a Engels, 7.9.1864 apud a BOTTOMORE, 2012, p. 264).

Esse embate entre historiadores e filósofos deve ser visto muito mais como resultado da convicção de parte a parte sobre novas formas de ver e de problematizar a história e, também, das objeções e dos limites (maioria dos quais pertinentes) que cada qual identificava na perspectiva do outro, do que por uma negação a esse ou aquele campo do saber. Ao fim e ao cabo, na crítica, na rejeição, mas, sobretudo, na assimilação, ambos contribuíram para o desenvolvimento de uma teoria da história. 
Não é minha pretensão apresentar aqui elementos novos a essa discussão. Muitos autores nacionais e estrangeiros vêm se debruçando sobre ela há tempo. ${ }^{1}$ No entanto, senti falta de um texto que, de maneira sintética, apresentasse essa complexa relação da história com a teoria e as reflexões filosóficas sobre a história. Julgo que as notas que seguem, dirigidas principalmente aos graduandos do curso de História, poderão contribuir como uma introdução à temática.

O texto está dividido em duas partes: na primeira, abordo a importância da teoria para os estudos históricos; na segunda, faço uma breve reflexão do difícil diálogo entre historiadores e filósofos sobre o conhecimento histórico até o século XIX. A filosofia da história que mencionarei aqui é aquela desenvolvida no âmbito do pensamento iluminista, de cunho especulativo, que buscava um sentido metafísico na história da humanidade. Portanto, não tratarei aqui nem das chamadas filosofias analíticas da história, nem das teorias da história formuladas pelos historiadores no século XX.

\section{A IMPORTÂNCIA DA TEORIA DA HISTÓRIA}

O significado primeiro de "teoria", na Grécia Antiga, era de contemplação, concepção mental, visão. Hoje a utilizamos para nos referir ao conjunto de regras ou leis aplicadas a uma área específica; um conhecimento de tipo especulativo, metódico e organizado, de caráter hipotético e sintético; um esquema de ideias que explica a prática.

A relação da historiografia com a teoria da história, nos diz José Carlos Reis, é marcada por tensão. Uma tensão que é profícua, quando o confronto entre a experiência vivida e a reflexão teórica é de reciprocidade, dialética, permitindo novas leituras da história. Todavia, é equivocada, quando ocorre aos historiadores desdenharem da discussão teórica, ou, ao contrário, quando os teóricos elaboram seus estudos apartados da base empírica. "Não há pesquisa histórica empírica sem o apoio implícito ou explícito da teoria e a teoria é estéril sem a pesquisa histórica. Uma se articula com a outra e se constituem reciprocamente" (REIS, 2006, p. 7).

Segundo Raymond Williams, a teoria "está sempre em ativa relação com a prática: uma interação entre as coisas feitas, as coisas observadas e a explicação (sistemática) delas. Isso permite uma distinção necessária entre teoria e prática, mas não requer sua oposição" (WILLIAMS, 2007, p. 394). No caso da história, portanto, a teoria seria o conjunto de princípios, gerais ou específicos, de conceitos, modelos, formulações abstratas que servem

\footnotetext{
${ }^{1}$ Para ficar apenas no âmbito das publicações brasileiras recentes, destaco, entre outras, as obras: Malerba (2010, 2013); Martins (2010); Parada (2012, 2013, 2014).
} 
como instrumento para vermos e explicarmos as ações humanas no tempo. De acordo com Jörn Rüsen,

O termo "teoria" acaba por abranger uma massa de argumentos muito heterogêneos, oriundos de campos tão diversos como a metodologia, a teoria do conhecimento, a filosofia da história, a hermenêutica, a crítica das ideologias, a sociologia da ciência e suas várias superposições interdisciplinares, todos pretendendo abordar o núcleo do que os historiadores consideram ser a essência de sua especialidade (2001, p. 18).

Tomemos como exemplo os eventos históricos conhecidos como as guerras de religião europeias do século XVI, que resultaram na Reforma. Até o surgimento do materialismo histórico (teoria elaborada por Karl Marx e Friedrich Engels nas décadas de 1840 e 1850), essas guerras eram vistas e explicadas por conflitos essencialmente religiosos, tendo como motivações centrais as querelas teológicas entre católicos, calvinistas, luteranos e outros. Não deixa de ser uma interpretação teórica já que os intérpretes do fenômeno acabavam por reproduzir os discursos daqueles agentes históricos, isto é, os problemas de ordem política e teológica. Segundo Marx e Engels, essas guerras não podiam ser compreendidas pelos discursos religiosos, mas por transformações estruturais da economia e da sociedade pelas quais a Europa passava naquele momento; pelas mudanças que se operavam no modo de produção daquelas sociedades. Como o próprio Engels disse:

Dentro daquilo a que se chama as guerras de religião (na Alemanha) no século XVI, tratava-se antes de tudo... de interesses materiais, de interesses de classes; e estas guerras eram lutas de classes; tal como as colisões interiores que se produziram mais tarde em Inglaterra e em França. Se as lutas de classe tinham, naquela época, um caráter religioso, se os interesses, as necessidades, as reivindicações das diferentes classes se dissimulavam sob a má cara da religião, isso nada altera à questão (...) (ENGELS Apud BOURDÉ \& MARTIN, 1990, p. 166).

"Modos de produção", "classes", "lutas de classes", "forças produtivas" são alguns dos conceitos que compõem a teoria do materialismo histórico e, por meio dela, os autores propõem uma nova forma de ver e interpretar as estruturas sociais e como se processa a mudança na história.

Vejamos outro exemplo: uma perspectiva dominante no século XIX e primeira metade do século XX valorizava a ação dos indivíduos, dos "fatos históricos", dos "eventos" (os franceses a chamaram histoire événementielle; nós costumamos dizer história factual), prendendo-se ao "tempo curto" dos acontecimentos. O ordenamento desses fatos resultava numa narrativa histórica linear com ênfase na diacronia. A Independência do Brasil, em 1822, 
seria explicada, dessa forma, pela sucessão de fatos marcantes que aconteceram naquele momento, como o grito do Ipiranga de Dom Pedro I, o "dia do fico", o retorno de Dom João VI para Portugal (1821), a revolução do Porto (1820), e outros eventos. Nas primeiras décadas do século $\mathrm{XX}$, a historiografia, tomando os fundamentos teóricos das ciências sociais (sobretudo da economia, sociologia, geografia e demografia), passou a perceber e interpretar os acontecimentos históricos no interior de contextos mais amplos denominados de "estruturas", "processos histórico-sociais", "sistemas". A interpretação histórica passou a ser apreendida na "longa duração", com ênfase agora não apenas na dimensão diacrônica dos fatos, mas, também, na dimensão sincrônica das estruturas. Nesse ponto de vista, os eventos políticos citados anteriormente que levaram à Independência do Brasil, só poderiam ser compreendidos na análise dos processos políticos, econômicos e socioculturais mais amplos no qual estavam inscritos e que se gestaram no final do século XVIII. Entre eles, destacam-se a Revolução Industrial inglesa, os movimentos revolucionários políticos da França e dos Estados Unidos da América, os ideais iluministas de liberdade e igualdade, os movimentos sociais, políticos e econômicos internos do Brasil etc. Portanto, os conceitos de "tempo curto", "longa duração", "diacronia", "sincronia", "estruturas", "sistemas" servem de instrumentos teóricos para a percepção da realidade histórica.

É possível escrever história sem recorrer a uma reflexão teórica elaborada? Sim, e essa tem sido, infelizmente, a prática mais habitual empregada pelos historiadores desde Heródoto até nossos dias. É claro que a historiografia mudou muito e se aperfeiçoou de lá para cá, fruto justamente das reflexões teóricas de historiadores, filósofos e outros pensadores. Todavia, pode-se afirmar, como afirmou Eric Hobsbawm que, ainda hoje, "teóricos de todos os tipos circulam ao redor dos tranquilos rebanhos de historiadores que se alimentam nas ricas pastagens de suas fontes primárias ou ruminam entre si suas publicações" (HOBSBAWM, 1998, p. 7).

Julio Aróstegui destaca três fatores que, em conjunto, contribuem para o atraso teórico-metodológico da atividade historiográfica. Em primeiro lugar, a própria natureza do seu objeto. A natureza do histórico é de extrema complexidade. Distintamente das ciências exatas e naturais, cujos pesquisadores têm diante de si o seu objeto de estudo para experimentar, testar e comprovar suas pesquisas, o historiador mira o seu objeto sempre de maneira indireta, por meio dos rastros e vestígios, que são os testemunhos deixados pelos homens. Além disso, aqueles cientistas estudam objetos perfeitamente mensuráveis, enquanto o historiador secciona e separa objetos (algum fenômeno social), que são por natureza imensuráveis e indivisíveis do todo no qual fazem parte. O químico, o biólogo e o físico, 
podem isolar seu objeto de investigação num laboratório; o historiador, não. Em segundo lugar, a vinculação da historiografia com o poder político, as instituições, a religião e outras ideologias. Como expressão da identidade de grupos, o discurso da História se subordina de maneira fácil, coerente e útil ao poder, em detrimento da reflexão filosófica. Por fim, a atitude dos historiadores que, de maneira geral, demostraram aversão a qualquer tipo de teorização, reforçando o caráter cronístico do discurso historiográfico. Não é exagerado dizer, portanto, que há uma tradição em "ingenuidade teórica e metodológica" dos historiadores (ARÓSTEGUI, 2006, p. 42 e 43).

O problema dessas histórias que desconsideram a teoria - trabalhos que até podem ser importantes do ponto de vista das informações empíricas que trazem, ou até mesmo serem agradáveis na leitura e com alta receptividade no mercado livreiro - é que elas escondem do leitor o processo de construção da narrativa histórica. Elas aparecem como neutras, fáceis, óbvias, lineares, desinteressadas, transparentes, objetivas e, geralmente, com pretensões totalizantes. Escondem, entretanto, por trás dessa ingenuidade, ou falsa ingenuidade, uma visão de história e as posições ideológicas (políticas, morais, religiosas, institucionais, étnicas etc.) do autor; são parciais, complexas, interessadas e subjetivas.

Observemos o que nos diz E. P. Thompson acerca do uso dos modelos na explicação da história:

Um modelo é uma metáfora do processo histórico, indicando suas partes significativas, a forma pela qual estão inter-relacionadas e a forma pela qual mudam. Por um lado, a história se mantém irredutível: permanece sendo tudo o que aconteceu. Por outro, a história não se torna história até que haja um modelo. A partir do momento em que as mais elementares noções de causa, processo ou padronização cultural entram em cena, algum modelo é adotado. Será bem melhor se for explicitado (THOMPSON, 2001, p. 155)2

Ou seja, o fato de alguns autores não darem a devida observância para a teoria ou não deixarem claro os pressupostos teóricos pelos quais fundamentam a sua investigação não quer dizer que ela esteja ausente. Pode manifestar-se irrefletidamente em forma de preconceitos, ideologias ou mesmo no uso inconsciente de teorias pré-estabelecidas.

A história não se apresenta de maneira transparente ao historiador, cabendo a ele apenas o trabalho de reunir as fontes, extrair dali os fatos históricos e organizá-los numa narrativa. Toda história é uma elaboração intelectual do historiador que, com base num

\footnotetext{
${ }^{2} \mathrm{O}$ materialismo histórico, teoria a qual Thompson se filia, constitui, de fato, um "modelo" de explicação da história. Contudo, historiadores não marxistas, talvez até por não obterem noutro lugar outro tipo de "modelo" paradigmático, ou por não aceitarem a possibilidade de aplicar modelos na história, prefiram fazer uso de formulações teóricas e conceitos específicos para problemas históricos específicos.
} 
posicionamento teórico, secciona o tempo e o espaço de investigação, acolhe, seleciona e analisa as fontes que irá trabalhar e elabora uma narrativa de caráter explicativo.

O processo de elaboração da pesquisa histórica está atravessado, do princípio ao fim, por subjetividades e outras incontornáveis aporias, independentemente da teoria que tomemos. Vejamos algumas delas:

- Objetividade/subjetividade: talvez a questão mais problemática do conhecimento histórico seja a da verdade. É possível um conhecimento objetivo na história? Se sim, por que ela tem de ser sempre reescrita? Quais os limites dessa objetividade? Se aquela perspectiva positivista do século XIX, que buscava dar à História o mesmo estatuto de cientificidade das ciências exatas e naturais não se sustenta mais, é bem verdade que há também muitas restrições a respeito de determinadas posições relativistas nas últimas décadas, que descartam qualquer possibilidade de um conhecimento objetivo do passado.

- Indivíduo/sociedade: qual o papel dos indivíduos na história? São eles os agentes principais das mudanças na história ou, ao contrário, são eles condicionados pelas instituições sociais, políticas, religiosas, econômicas e culturais? Como já assinalamos acima, a historiografia no século XIX, de uma maneira geral, tendeu a valorizar a ação dos indivíduos na história. Em meados do século XX, prevaleceu uma visão que privilegiava as estruturas e os condicionamentos sociais e econômicos sobre os indivíduos. Atualmente, as teorias sociais, sejam elas estruturalistas, funcionalistas, funcional-sistêmica ou marxista tendem a enfatizar a relação dialética virtual entre ação humana e estruturas, entre o sujeito e as relações sociais pré-existentes (ARÓSTEGUI, 2006, p. 261).

- Permanência/ruptura: o desenvolvimento histórico é incompatível tanto com a existência de permanência absoluta quanto de ruptura absoluta de uma estruturação social e aí reside, também, um dos grandes problemas da análise histórica, pois, mudanças que se operam em determinada dimensão histórico-social não se verificam em outras. A teoria da história deve propor explicações sobre como ocorrem as mudanças na história.

- Ideia/existência: essa discussão é tão antiga quanto a da própria Filosofia. Para citar apenas alguns dos pensadores mais contemporâneos - e, respeitando, evidentemente, as abordagens teóricas próprias de cada um deles a esse respeito -, ela aparece em K. Marx (idealismo/existência), em R. Chartier (representação/prática), em M. Foucault (palavras/coisas) e em R. Koselleck (história dos conceitos/história social). Todo e qualquer estudo sobre as sociedades humanas depara-se com o problema da complexa relação entre o campo da vida material e das ações que os homens efetivamente realizam e o campo das 
ideias. Qual o mais importante na história? Há algum sentido de determinação de um desses campos sobre o outro?

- História/memória: ambas constituem um movimento mental do presente ao passado; ambas procuram ressignificar o ocorrido. Por esse motivo, verificamos no senso comum, o uso indiscriminado destas ciências. Todavia, não são a mesma coisa, e é importante que se estabeleça a diferença. A história é o estudo sistemático e racional (ainda que nunca plenamente objetivo) das sociedades humanas; a memória é o instrumento mental, mais individual do que coletivo, de ressignificação do passado, de caráter marcadamente psicológico, ideológico e subjetivo. Ainda assim, não há como negar as múltiplas e complexas relações possíveis entre história e memória. Há hoje, por exemplo, um campo de estudo conhecido como história social da memória.

- Passado/presente, ou simplesmente tempo histórico: alguns teóricos costumam dizer que o problema do tempo constitui, talvez, o único grande problema da história. Podemos afirmar que todas as aporias mencionadas acima estão permeadas de uma maneira ou de outra pelo problema do tempo. Para além do ordenamento temporal dos fatos na sucessão temporal (a cronologia) e da identificação das rupturas e permanências (a periodização), os historiadores devem ainda perceber os diferentes ritmos do tempo.

Teríamos ainda outros problemas fundamentais a considerar como os sentidos de totalidade (os processos históricos são indivisíveis e englobam todas as dimensões humanas, sociais, políticas, econômicas e mentais); de universalidade (a história é de todos os homens e não apenas de determinados grupos ou nações); de sistema (cada parte vincula-se as outras partes e ao todo interagindo reciprocamente) (ARÓSTEGUI, 2006, p. 292). Cada um desses pontos demandaria por si só extensa e profunda reflexão, o que não é o caso de fazermos aqui. O objetivo em assinalá-las é justamente de mostrar alguns dos principais problemas teóricos que os historiadores têm de enfrentar em suas pesquisas. Embora essas reflexões venham sendo largamente debatidas contemporaneamente, é preciso que se diga que algumas delas foram já colocadas pelos filósofos e historiadores dos séculos XVIII e XIX, senão de maneira sistematizada, pelo menos como ponto de partida para formulações teóricas posteriores mais complexas.

\section{INTERFACES (DIFÍCEIS) ENTRE A HISTÓRIA E A FILOSOFIA}

Não obstante a História e a Filosofia serem filhas de um mesmo espaço e tempo histórico, a Grécia Antiga, o diálogo entre as duas, quando houve, nunca foi muito fácil e 
tranquilo. Podemos dizer que somente no século XX esses dois campos do saber alcançaram uma interlocução mais estreita, um diálogo mais inteligível e profícuo no que diz respeito ao conhecimento histórico. Talvez, essa difícil relação resulte da própria complexidade do objeto de estudo da história, como dito anteriormente, e, por conseguinte, da dificuldade (ou relutância?), tanto da parte dos historiadores de formularem uma teoria da história, quanto da parte dos filósofos de incluírem a história como objeto possível de ser racionalizado.

É na segunda metade do século V a.C., no pequeno mundo egeu onde tinha desabrochado a arte dos poetas trágicos e despertava a especulação dos filósofos, que nasce a história. Heródoto (aprox. 485-425 a.C.), de quem se repete a porfia, desde Cícero, que é o 'pai da história', foi contemporâneo de Eurípides e de Sócrates. [...] Contudo, se à primeira vista a poesia, a escultura e o pensamento gregos se aproximam da perfeição, o mesmo não acontece com a história, gênero híbrido (CARBONELL, 1992, p. 11).

Que imperfeições híbridas da História são essas apontadas por Carbonell? Heródoto é legitimamente apontado como aquele que promove uma primeira ruptura com a literatura épica, com a figura do Aedo (o poeta-cantor) que, por meio dos deuses e das musas narra e explica o mundo dos homens e do sagrado (TORRANO, 2003, p. 16). ${ }^{3}$ Com Heródoto, os homens passam a ocupar o primeiro plano da narrativa. Todavia, a ruptura não é radical e o lendário e o mitológico fazem-se ainda presentes em suas Histórias. Tucídides (aprox. 460395 a.C.) aprofunda as regras do estabelecimento da verdade e, de admirador e discípulo que era de Heródoto, passa depois a desqualificá-lo chamando-o de mitólogo. Plutarco (45-123 d.C.) foi ainda mais severo na avaliação que fez de Heródoto apresentando-o como mentiroso (CARBONELL, 1992, p. 19-20).

Tais qualificativos, aparentemente contraditórios, de "pai da história" e, portanto, da verdade e, ao mesmo tempo, "pai de mentiras" nos remete a própria "ambivalência do discurso histórico, sempre tensionado entre o real e a ficção" (DOSSE, 2003, p. 19). ${ }^{4}$ E as imperfeições da história não vinham apenas da interferência da literatura, mas também das tentações - ou da subordinação - ao poder, à política, à religião e às concepções morais e éticas.

A Filosofia, na época de seu nascimento, apresentava os seguintes traços definidores, conforme nos mostra Marilena Chauí:

\footnotetext{
${ }^{3}$ Esclarece o autor que, "Nesta comunidade agrícola e pastoril anterior à constituição da pólis e à adoção do alfabeto, o Aedo (i.e., o poeta-cantor) representa o máximo poder da tecnologia de comunicação. Toda visão de mundo e consciência de sua própria história (sagrada e/ou exemplar) é, para este grupo social, conservada e transmitida pelo canto do poeta".

${ }^{4} \mathrm{O}$ autor faz referência aqui ao pensamento de François Hartog.
} 
A ideia de que o conhecimento verdadeiro deve encontrar as leis e os princípios universais e necessários do objeto conhecido e deve demonstrar sua verdade por meio de provas ou argumentos racionais (...).

A ideia de que a natureza segue uma ordem necessária e não casual ou acidental. Ou seja, a ideia de que ela opera obedecendo a leis e princípios necessários (isto é, não poderiam ser outros ou diferentes do que são) e universais (quer dizer, são os mesmos em toda a parte e em todos os tempos) (CHAUÍ, 2011, p. 34-35, grifos da autora).

Como incluir o conhecimento histórico nesses princípios? Heródoto e Tucídides procuraram em suas obras demonstrar suas verdades "por meio de provas ou argumentos racionais", mas não apresentaram leis nem princípios universais e necessários de seus objetos de estudo. A explicação de Heródoto para as Guerras Médicas (490-479 a.C.), entre gregos e persas, não servia para que Tucídides compreendesse e explicasse a Guerra do Peloponeso (431-404 a.C.), entre atenienses e espartanos.

Enquanto a História buscava explicar fenômenos singulares, únicos, irrepetíveis, a Filosofia tratava de encontrar as recorrências, as leis e princípios verdadeiros e válidos para toda a parte e em todos os tempos. O conhecimento histórico seria, portanto, não filosófico. Aristóteles, na Poética, afirmou inclusive que "a Poesia encerra mais filosofia e elevação do que a História; aquela enuncia verdades gerais; esta relata fatos particulares" (ARISTÓTELES, 2005, p. 28).

Nos períodos subsequentes, nem historiadores nem filósofos avançaram muito na fundamentação teórica do conhecimento histórico. Durante o período medieval prevaleceu para ambos a concepção providencialista da história humana, segundo a qual Deus dispunha do poder de intervir e modificar o seu curso. A historiografia, enclausurada nos domínios da Igreja, dos mosteiros, ficou refém da concepção cristã da história.

No alvorecer da Época Moderna, a invenção da imprensa por Gutemberg, a descoberta do Novo Mundo e o desenvolvimento do comércio em escala mundial sinalizam as profundas transformações pelas quais a sociedade europeia estava atravessando, em todos os seus níveis. O retorno ao antigo e à centralidade do homem no mundo, que caracterizam o Renascimento e o Humanismo, abrem caminho para a crítica das instituições políticas e religiosas e das ideias que lhes davam legitimidade.

Essa abertura crítica permitiu, por exemplo, que o humanista romano Lorenzo Valla, por volta de 1440, protegido pelo príncipe de Nápoles, Alfonso de Aragon, contestasse a autenticidade do documento conhecido como "Doação de Constantino". Por muito tempo o Vaticano justificava seus territórios na península itálica por uma doação feita à Igreja pelo imperador romano Constantino no século IV d.C. Observando os erros linguísticos, a 
paleografia, o tipo de papel e equívocos de conteúdo no texto, Valla provou que o documento não poderia ser daquele tempo, ou seja, tratava-se de uma grosseira falsificação feita provavelmente no século VIII de nossa era. O que se colocava em jogo aí era o discurso de verdade, não mais amparado na autoridade suprema e inquestionável da igreja, mas na do erudito especialista (DOSSE, 2003, p. 27-31; CARBONELL, 1992, p. 61).

A Reforma Protestante, além do embate de ideias religiosas e políticas que representou, pode ser considerada também como uma disputa pela interpretação histórica mais correta das Escrituras:

A controvérsia desliza rapidamente do plano teológico (...) para o plano histórico. Cada qual esquadrinha as bibliotecas e acumula os documentos com outras tantas provas da sua verdade. (...)

Da controvérsia nasce assim uma nova história eclesiástica que perdeu o seu caráter sagrado e se tornou profana, erudita e demonstrativa (CARBONELL, 1992, p. 71-72).

Outro marco decisivo para a constituição da erudição metódica foi a publicação, em 1681, da obra A Diplomática de autoria do padre beneditino Jean Mabillon. Fundava-se aí a ciência da diplomática, estipulando as regras que permitem distinguir com clareza a autenticidade ou falsidade das cartas e títulos antigos, também chamados de diplomas. Segundo ele, a primeira regra da história seria a busca da verdade: "como o amor da justiça é a primeira qualidade de um juiz, também a primeira qualidade de um historiador é o amor e a procura da verdade das coisas passadas" (Apud DOSSE, 2003, p. 34). Para Marc Bloch, nesse ano - 1681 - "a crítica de documentos foi definitivamente fundada" (BLOCH, 2001, p. 90).

Paleografia, filologia, numismática, hermenêutica e diplomática - o gosto pelo antigo fez surgir atividades como a dos antiquários, colecionadores de todos os tipos, inclusive de manuscritos, e arqueólogos (nesse momento, tudo mais em função do valor comercial dos "tesouros" do que da ciência) - constituíram-se em especialidades fundamentais para o surgimento da história científica no século XIX. ${ }^{5}$

\footnotetext{
${ }^{5}$ Paleografia - "É a ciência que lê e interpreta as formas gráficas antigas, determina o tempo e o lugar em que foi escrito o manuscrito, anota os erros que possa conter o mesmo, com o fim de fornecer subsídios à História, à Filologia, ao Direito e a outras ciências que tenham a escrita como fonte de conhecimento." (ACIOLI, 1994, p. 5); Filologia - "Estudo científico do desenvolvimento de uma língua ou de famílias de línguas, em especial a pesquisa de sua história morfológica e fonológica baseada em documentos escritos e na crítica dos textos redigidos nessas línguas (p.ex., filologia latina, filologia germânica etc.)" (HOUAISS, 2001); Numismática Ciência que tem por objeto de estudo as moedas e medalhas antigas (HOUAISS, 2001); Hermenêutica - A arte ou teoria da interpretação. Originalmente relacionado mais a interpretação dos textos sagrados, o termo adquiriu sentido mais amplo e passou a ser empregado para análise de todo tipo de texto. São regras ou critérios para entender o que um autor quis dizer "realmente" (AUDI, 2006).
} 
No século XVII, nasce a Filosofia Moderna. Entre os principais pensadores desse período, também conhecido como do Grande Racionalismo Clássico, estão: Francis Bacon, Descartes, Galileu, Pascal, Hobbes, Espinosa, Leibniz, Malebranche, Locke e Newton. Deixando de lado aqui as especificidades teóricas de cada um deles é possível, segundo nos diz Marilena Chauí, destacar o seguinte princípio filosófico fundamental comum nesses pensadores: de que "a realidade é racional porque é um sistema ordenado de causalidades físico-matemáticas perfeitas e plenamente conhecíveis pela razão humana" (CHAUÍ, 2011, p. 61-62). Dessa filosofia surgiriam as ciências modernas (Matemática, Física, Astronomia, Química, Biologia, Política, Psicologia, dentre outras).

Com base nesses princípios estritamente racionalistas, a História não tinha ainda seu espaço na reflexão filosófica. No Discurso do Método, René Descartes (1596-1650), afirmava:

[...] as fábulas fazem imaginar como possíveis muitos eventos que não o são, e mesmo as histórias mais fiéis, se não mudam nem alteram o valor das coisas para torná-las mais dignas de serem lidas, ao menos omitem quase sempre as circunstâncias mais baixas e menos ilustres, de onde resulta que o resto não parece tal qual é [...] (DESCARTES, 1987, p. 31).

Dizia ainda: as línguas, a Geografia e a História são adquiridas "sem nenhum discurso de razão", recorrendo apenas à memória (DESCARTES, 1987, p. 31). Pascal (1623-1662) considerava a história "incapaz de progresso" porque "não releva nem do raciocínio nem da experiência, mas somente do princípio da autoridade”. Malebranche (1638-1715), por sua vez, dizia que os conhecimentos históricos eram "vãos e infrutíferos" (Apud CARBONELL, 1992, p. 76).

Mas os filósofos eram leitores de história, tanto para informação, quanto para distração. Leibniz - conta-nos Marc Bloch - "quando das abstratas especulações matemáticas ou da teodiceia passava para o deciframento dos velhos documentos ou das velhas crônicas da Alemanha imperial, experimentava, como todos nós, essa 'volúpia de aprender coisas singulares"” (BLOCH, 2001, p. 44).

Tal disposição dos filósofos perante o conhecimento histórico mudaria no Século das Luzes. Diante das revoluções científicas dos renascentistas e humanistas; e de uma consciência histórica que escapava em muito os limites da memória e da oralidade (formarase já nessa época a dimensão tripartite da história da humanidade - Antiguidade, Idade Média, Época Moderna), não era mais possível desconsiderar o problema da longa história da humanidade, seus avanços e recuos, a ascensão e queda dos grandes impérios, as grandes 
civilizações, enfim, seu processo evolutivo. A própria filosofia precisava ser pensada e compreendida no tempo, isto é, na história.

Os filósofos iluministas como Voltaire, Condorcet, Kant, Herder e Hegel, vão, assim, produzir suas filosofias da história - reflexões sobre a história, mas de modo muito distinto dos historiadores. Nessas filosofias, as histórias particulares, de uma guerra, de um reino, de um indivíduo, que os historiadores produziam, só tinham interesse se pensadas como uma totalidade, na História, esse singular-coletivo, entendido como o "conjunto do emaranhado das relações político-sociais deste mundo, em todas as suas dimensões temporais" (KOSELLECK, 2013, p. 38). Segundo Karl Löwith, as filosofias da história foram um esforço de "interpretação sistemática da história universal de acordo com um princípio segundo o qual os acontecimentos e sucessões históricos se unificam e dirigem para um sentido final" (1977, p. 15).

Essas diferenças de perspectivas ultrapassaram em muito o simples debate teórico, significaram uma profunda mudança na percepção do tempo histórico no século XIX. Enquanto o pensamento filosófico, em sintonia com as revoluções burguesas, projetava-se para o futuro, a historiografia foi conservadora e voltava-se para o passado. A Revolução Francesa representava para Kant e Hegel a vitória da Razão, da justiça, da ordem e da moralidade (REIS, 2003, p. 2).

Os filósofos buscaram o sentido, a Ideia, a Razão, o fio condutor da História. Os historiadores, sobretudo os alemães, rejeitaram essa visão filosófica da história. Ranke deixa bem clara a diferença de posições:

Antes de tudo, a filosofia sempre volta-nos para a afirmação da ideia suprema. A história, por outro lado, traz-nos para as condições da existência. A primeira confere importância ao interesse universal; a última, ao particular. A primeira considera o desenvolvimento essencial e vê cada particular somente como uma parte de um todo. A história volta-se com simpatia também para o particular. A filosofia constantemente o rejeita: estabelece a condição com a qual ela o aprovaria no futuro remoto. Por sua natureza, a filosofia é profética, dirigida adiante. A história vê o bem e o benefício naquilo que existe. Tenta compreendê-lo e olha para o passado (RANKE, 2010, p. 145).

Para ele, assim como para outros historiadores daquele século, não havia um sentido $a$ priori na história, nem uma Ideia ou Razão válida universalmente. A história era um conhecimento a posteriori, afirmavam, e ao historiador cabia avaliar uma época e uma nação, segundo seus próprios critérios e valores, ou seja, segundo sua própria historicidade. 
A "história científica", que se consolida no século XIX, é, portanto, antimetafísica. O que predomina entre os historiadores é o chamado "espírito positivo", isto é, só é possível conhecer as relações de causa e efeito dos fenômenos observáveis. "O 'a-histórico', o substancial, o imutável das filosofias da história é inverificável, logo, não ‘científico'. O objeto do historiador é o localizado e datado, o relativo a uma situação espaço-temporal, irrepetível, singular: o evento", assinala José Carlos Reis, (1999, p. 6).

Contudo, como dito na primeira parte deste artigo, refletida ou irrefletidamente, os historiadores se amparam em algum modelo ou teoria para comporem suas histórias. A rejeição por parte deles às filosofias da história ficava muito mais no plano das declarações do que no das práticas. As ideias filosóficas de progresso, de civilização, de cultura e mesmo de sentido histórico foram de alguma forma incorporadas nas narrativas historiográficas oitocentistas. A pretensa atitude imparcial e objetiva daqueles historiadores encobria, na verdade, posicionamentos políticos, ideológicos e intelectuais, como não poderia deixar de ser (BOURDÉ e MARTIN, 1983, p. 115). Além disso, é preciso dizer que muitos deles demostraram grande interesse nas reflexões filosóficas. Segundo Chateaubriand (1768-1848), os historiadores do seu tempo poderiam ser classificados em três escolas: a narrativa, a fatalista e a filosófica (CARBONELL, 1992, p. 96).

É enganador pensar também que o campo de estudo conhecido por "filosofias da história", nos séculos XVIII e XIX, constituísse um objeto muito bem delimitado, com problemas conceituais idênticos, nos quais cada filósofo dava a sua contribuição. Embora tenha destacado aqui alguns pontos em comum, havia por certo perspectivas bem peculiares sobre como cada um deles inseria a história em seus sistemas filosóficos mais abrangentes.

No final do século XIX, filósofos como Dilthey, Croce e, mais tarde, Collingwood, começaram a defender que a história e as ciências humanas, de um modo geral, deveriam constituir um campo de estudos autônomo, com suas regras e métodos próprios, distintos daqueles que serviam de base para as ciências exatas e naturais. Eles viram também, nos diz Patrick Gardiner, que,

a história pode ser um objeto de indagação filosófica num sentido bem diferente do que era considerado pelos filósofos-historiadores de tipo especulativo. Não se impuseram a tarefa de tentar descobrir um "sentido" ou um modelo na totalidade do processo histórico, antes se concentraram na discussão das vias pelas quais os historiadores de profissão interpretam, de fato, a sua matéria, tentando revelar os pressupostos que subjazem a qualquer porção de autêntico pensamento histórico (1995, p. 9). 
A negação das filosofias da história de cunho especulativo e a busca de problemas relacionados aos procedimentos metodológicos, à narrativa e à cientificidade da história deu origem ao que, no século XX, veio a se chamar de Filosofia Analítica (ou Crítica) da História. Trata-se de um campo de estudos atravessado pela diversidade de problemas vinculados à teoria do conhecimento, à metafísica, à história propriamente dita, à teoria social e à crítica literária. ${ }^{6}$ Abre-se aqui uma série de outras questões teóricas complexas sobre as quais filósofos e historiadores vêm se ocupando contemporaneamente.

\section{CONSIDERAÇÕES FINAIS}

No século XIX, a construção de uma história científica por parte dos historiadores ancorava-se muito mais na já longa tradição dos eruditos especialistas - hermeneutas, paleógrafos e filólogos - do que na filosofia. O resultado mais concreto dessa historiografia foi a consolidação de uma metodologia da pesquisa histórica baseada na crítica documental, que não deixa de ser uma "teoria" - uma "teoria do documento" -, tão importante nas reflexões da atividade historiográfica atual.

A filosofia, por sua vez, esforçou-se por encontrar leis gerais, a racionalidade dos processos históricos. Fatos singulares e irrepetíveis só interessavam na medida em que servissem para explicar a lógica interna do movimento histórico universal. "Haveria um sentido na história da humanidade?", questionavam eles. No bojo dessas filosofias, outras questões vinham sendo gestadas. Entre elas, a da história vista não apenas como uma sucessão de fatos políticos-militares, mas como uma totalidade de fenômenos, a problemática da cultura dos povos, questões ligadas à própria racionalidade e subjetividade do conhecimento historiográfico. Todas elas fundamentais para o surgimento de uma história mais reflexiva.

Se, no século XIX, esse debate intelectual em torno da cientificidade da história, com historiadores por um lado e filósofos por outro, foi difícil, no século XX, a interlocução entre ambos se tornou não só possível, mas necessária para o desenvolvimento de uma teoria da história.

\section{REFERÊNCIAS BIBLIOGRÁFICAS}

ACIOLI, Vera Lúcia Costa. A escrita no Brasil Colônia: um guia para a leitura de documentos manuscritos. Recife: UFP/Fundação Joaquim Nabuco/Massananga, 1994.

\footnotetext{
${ }^{6}$ Sugiro como uma introdução à temática, o livro de Verônica Tozzi (2009), a segunda parte da obra de Patrick Gardiner (1995) e o artigo de Estevão de Rezende Martins (1989).
} 
ARISTÓTELES. A Poética Clássica. Trad. Jaime Bruna. 12 ed. São Paulo: Cultrix, 2005.

ARÓSTEGUI, Julio. A pesquisa histórica: teoria e método. Trad. Andréa Dore. Bauru, SP: Edusc, 2006.

AUDI, Robert (Dir). Dicionário de Filosofia de Cambridge. São Paulo: Paulus, 2006.

BLOCH, Marc. Apologia da história, ou, o ofício do historiador. Trad. André Telles. Rio de Janeiro, Zahar, 2001.

BOTTOMORE, Tom (Ed.). Dicionário do pensamento marxista. 2 ed. Rio de Janeiro, Zahar, 2012.

BOURDÉ, Guy; MARTIN, Hervé. As escolas históricas. Tradução Ana Rabaça. Lisboa: Europa-América, 1983.

CARBONELL, Charles-Olivier. Historiografia. Trad. de Pedro Jordão. Lisboa: Teorema, 1992.

CHARTIER, Roger. A história cultural: entre práticas e representações. Trad. Maria Manuela Galhardo. 2 ed. Lisboa: DIFEL, 2002.

CHAUÍ, Marilena. Convite à Filosofia. 14 ed. São Paulo: Ática, 2011.

DURANT, Will. A história da filosofia. Trad. Luiz Carlos do Nascimento Silva. Rio de Janeiro: Nova Cultural, 1996

DESCARTES, René. Discurso do Método. Trad. J. Guinsburg e Bento Prado Júnior. In: Descartes. 4 ed. São Paulo: Nova Cultural, 1987 (Col. Os Pensadores).

DOSSE, François. A história. Trad. Maria Elena Ortiz Assumpção. Bauru, SP, EDUSC, 2003. FOUCAULT, Michel. As palavras e as coisas: uma arqueologia das ciências humanas. Trad. Salma Tannus Muchail. 8 ed. São Paulo: Martins Fontes, 2000.

GARDINER, Patrick. Teorias da história. 4 ed. Lisboa: Fundação Calouste Gulbenkian, 1995.

HOBSBAWM, E.J. Sobre história. Trad. Cid Knipel Moreira. São Paulo: Companhia das Letras, 1998.

HOUAISS, A. Dicionário HOUAISS da Língua Portuguesa. Rio de Janeiro: Objetiva, 2001.

KOSELLECK, Reinhart. O conceito de história. Trad. René Gertz. Belo Horizonte: Autêntica, 2013.

Futuro passado: contribuição à semântica dos tempos históricos. Trad. Wilma Patrícia Maas e Carlos Almeida Pereira. Rio de Janeiro: Contraponto; EdPUC-Rio, 2006.

LANGLOIS, C.; SEIGNOBOS, C. Introdução aos estudos históricos. Trad. Laerte de Almeida Morais. São Paulo: Renascença, 1946.

LÖWITH, Karl. O sentido da história. Lisboa: Edições 70, 1977. 
MALERBA, Jurandir (Org). Lições de História: o caminho da ciência no longo século XIX. Rio de Janeiro; FGV, 2010.

(Org). Lições de História: da história científica à crítica da razão metódica no limiar do século XIX. Porto Alegre: FGV, Edipucrs, 2013.

MARTINS, Estevão de Rezende (Org). A história pensada: teoria e método na historiografia europeia do século XIX. São Paulo: Contexto, 2010.

_. Filosofia analítica da história. In: CARVALHO, M. C. M (org). Paradigmas filosóficos da atualidade. Campinas, SP: Papirus, 1989.

MARX, Karl; ENGELS, Friedrich. A ideologia alemã: crítica da mais recente filosofia alemã em seus representantes Feuerbach, B. Bauer e Stirner, e do socialismo alemão em seus diferentes profetas (1845-1846). Trad. Rubens Enderle, Nélio Schneider, Luciano Cavini Martorano. São Paulo: Boitempo, 2007.

MONOD, Gabriel. Do progresso dos estudos históricos na França desde o século XVI. In: MALERBA, Jurandir (Org). Lições de História: o caminho da ciência no longo século XIX. Rio de Janeiro; FGV, 2010.

PARADA, Maurício (Org). Os historiadores clássicos da história, vol. 1: de Heródoto a Humboldt. Petrópolis, RJ: Vozes, PUC-Rio, 2012.

(Org). Os historiadores clássicos da história, vol. 2: de Tocqueville a Thompson. Petrópolis, RJ: Vozes, PUC-Rio, 2013.

(Org). Os historiadores clássicos da história, vol. 3: de Ricoeur a Chartier. Petrópolis, RJ: Vozes, PUC-Rio, 2014.

RANKE, Leopold von. Sobre o caráter da ciência histórica. In: MALERBA, Jurandir (Org). Lições de História: o caminho da ciência no longo século XIX. Rio de Janeiro: FGV, 2010. REIS, José Carlos. A história, entre a Filosofia e a Ciência. 2 ed. São Paulo: Ática, 1999. Wilhelm Dilthey e a autonomia das ciências Histórico-sociais. Londrina: Eduel, 2003. História \& teoria: historicismo, modernidade, temporalidade e verdade. 3 ed. Rio de Janeiro: FGV, 2006.

RÜSEN, Jörn. Razão histórica: teoria da história: fundamentos da ciência histórica. Trad. Estevão de Rezende Martins. Brasília: EdUnB, 2001.

TOZZI, Verónica. La historia según la nueva filosofia de la historia. Buenos Aires: Prometeo Libros, 2009.

THOMPSON, E.P. As peculiaridades dos ingleses (trad. Alexandre Fortes e Antônio Luigi Negro). In: As peculiaridades dos ingleses e outros artigos. Campinas, SP: Ed. UNICAMP, 2001 . 
TORRANO, Jaa. O mundo como função das musas. In: HESÍODO. Teogonia, a origem dos deuses. 5 ed. São Paulo: Iluminuras, 2003.

WILLIAMS, Raymond. Palavras-chave: um vocabulário de cultura e sociedade. Trad. Sandra Guardini Vasconcelos. São Paulo: Boitempo, 2007.

ARTIGO ENVIADO EM: 30/07/2016 ARTIGO ACEITO PARA PUBLICAÇÃO EM: 12/02/2017 